\title{
Test of an innovative method to prepare coffee powder puck, improving espresso extraction reliability
}

\author{
Giulia Angeloni ${ }^{1} \cdot$ Lorenzo Guerrini $^{1} \cdot$ Piernicola Masella $^{1} \cdot$ Andrea Dionisio $^{2} \cdot$ Riccardo Gatti $^{2} \cdot$ Alessandro Parenti $^{1}$
}

Received: 8 July 2021 / Revised: 17 September 2021 / Accepted: 18 September 2021 / Published online: 30 September 2021

(c) The Author(s) 2021

\begin{abstract}
Coffee powder is obtained with a grinding machine. Espresso coffee is prepared when hot water is forced under pressure through the puck of coffee powder, and the optimal espresso flow rate is $1 \mathrm{~g} \mathrm{~s}^{-1}$. However, this flow rate can change for different extractions, forcing baristas to frequently change the setup of the grinder. Grinding grade is one of the most important sources of variation in the quality of espresso. This study tests an innovative method to prepare coffee powder puck, designed to reduce variability in flow rate between extractions. The method is based on stratified layers of ground coffee with different granulometry, and it was tested in three trials with different coffees and grinders. The flow rate associated with the new method (Patent WO/2020/148258- PCT/EP2020/050773) was more stable than the rate in a conventional system, reliability was optimized by placing larger coffee particles at the bottom, and finer particles at the top of the filter basket.
\end{abstract}

Keywords Flow rate $\cdot$ Particle size $\cdot$ Grinder $\cdot$ Barista $\cdot$ Robust design

\section{Introduction}

According to the International Coffee Organization, beverages prepared from roasted coffee beans are widely consumed all over the world, and coffee consumption continues to increase [1]. When a beverage is prepared, a specific quantity of ground coffee, usually referred to as a 'dose', is used. The importance of using dosing coffee correctly is not to be underestimated. It must be constant and repeatable because this quantity, which is related to grinding, influences extraction behavior and the final beverage.

Grinding consists of reducing beans to obtain a homogeneous powder. The primary objective is to increase the specific extraction surface or, more specifically, to increase the interface between water and coffee, to facilitate the transfer of soluble and emulsifying substances into the brew [2]. During extraction, caffeine and other important bioactive compounds are partially removed; their content varies

Lorenzo Guerrini

lorenzo.guerrini@unifi.it

1 DAGRI, Department of Agriculture, Food, Environment and Forestry, University of Florence, Piazzale delle Cascine 16, 50144 Firenze, Italy

2 La Marzocco S.R.L, Via La Torre 14/H-Loc. La Torre, 50038 Scarperia (FI), Italy according to several factors, such as the brewing technique and the recipe [3].

Coffee powder is obtained using dedicated grinders. Flat and conical burr grinders are used in both home and industrial systems. A flat burr grinder uses two flat rings that are placed parallel to each other, while a conical grinder uses two cone-shaped rings that are placed within each other. In both types, one ring is stationary while the other is rotated by a motor. Several models have an accumulation tank for the ground powder, while others implement a dosing system in which the ground powder is used immediately (ondemand systems).

Ground coffee powder is characterized by particles or granules that have a theoretical size. Granules may be expressed as a profile, called a particle size curve, with a bimodal distribution. The high peak is called the "first modal', while the low peak is called the 'second modal'. Particle diameter can range from a few micrometers to $1000 \mu \mathrm{m}$. Volatiles are easily released, and chemical compounds are quickly dissolved in hot water, giving coffee its characteristic aroma [4]. Various brewing methods require beans to be ground into particles with a consistent size, and extraction studies show that different brewing methods (e.g. espresso, French, or other filter methods) require a certain particle size distribution [5-9]. 
Espresso is one of the most popular coffee beverages. The method uses a pressure difference to drive hot water $\left(90 \pm 5^{\circ} \mathrm{C}\right)$ through a compacted and pressed cake of roasted ground coffee to extract soluble material from the matrix $[10,11]$. Illy and Navarini [12] summarize the preparation of espresso into three steps: (i) grinding of roasted coffee, (ii) dosing and tamping, and (iii) percolation. Extraction is dynamic, and the optimal flow rate is about $30 \mathrm{~g}$ over $30 \mathrm{~s}$. The brewing process mixes a double extraction mechanism: a washing phase producing a rapid extraction of free solubles at the particle surface and a diffusion phase, extracting internal solubles [13].

The flow rate is initially low, due to the cake's resistance to water passing through it, but increases as extraction progresses.

The particle size of the ground coffee is critically important since it affects the flow rate. The flow rate, in turn, affects both the extent of the contact between the water and the coffee, and its duration, changing the whole extraction kinetic [14]. The short extraction time means that ground beans should contain a minimum percentage of fine particles, to achieve sufficient pressure in the coffee cake, and produce a full body and delicate crema $[15,16]$. Furthermore, several studies have noted not only the importance of the grinding process, as which different ground sizes affected the flowability of the powder [17], but also the chemical composition and sensory properties of the beverage [18-20]. These observations underline that the particle size distribution of coffee powder dramatically affects espresso quality.

The dose of ground coffee is loaded into a filter basket, normally in the form of an open cup, which has a bottom with micro-perforations. Typically, it is pressed into the filter basket to form a puck. The impact of particle size and placement within an espresso filter basket is an active area of interest and debate in the coffee community [21].

As demonstrated by several studies, there is a strict relationship between the (constant) percolation flow rate and the size distribution of coffee particles. A coffee beverage produced with a greater number of fine particles results with a slower flow rate and the resulted in a coffee beverage 'shorter' compared to a brew made from a powder where there is a greater amount of large particles, for the same extraction time [22] [23]. Too-fine powder results in over-extracted coffee for the large contact time between water/powder, while a too-coarse grind increases the flow rate, resulting an under-extracted coffee beverage due to the shorter contact time between water/powder [2].

Severini and co-authors [24] showed that the most important source of variation in espresso coffee quality was the grinding grade. Their experiments found that this factor accounted for at least $80 \%$ of variation. Variability in the particle size distribution of ground coffee significantly affected the percolation rate, caffeine content, solids content,
$\mathrm{pH}$ and acidity. This variation was argued to be the consequence of changes in the microstructural properties of the coffee cake, such as porosity and the percolation pathway.

In practice, each barista adjusts their grinder to obtain a particle size which, in his/her experience, produces a correct flow rate and, consequently, an optimum beverage. Whether the machine is equipped with flat or conical grinders, the smaller the distance between the grinding plates, the greater the number of fine particles and the fewer the number of large particles. The opposite is true as the distance between the grinding plates increases (i.e., fewer fine particles and more large particles). Usually, a barista adjusts the grinding setting if they observe a difference in the flow rate. This change can be due to the use of a different brand of coffee (variability between brands) or a different packet of the same brand (variability between batches of the same brand), but often it is due to uncontrollable environmental or operative conditions.

Typically, the particle size distribution is a function of environmental conditions, the physical properties of the coffee bean, and the type of grinder [24]. Particle size itself determines the extraction accessory (e.g., filter baskets, a distributor and tamping), which should be tuned in a specific way in order to extract a good espresso coffee [25].

Therefore, the overall aim of this study is to reduce variability in flow rate between extractions, through the development of an innovative method to prepare coffee powder puck. The first goal is to reduce the sensitivity of the grinder to variation in the raw material. A second objective is to develop a method that can stabilize the instantaneous flow rate of the espresso coffee that is obtained using the ground product.

\section{Materials and methods}

The study tested the innovative method to prepare coffee powder puck described in patent WO/2020/148258 PCT/ EP2020/050773, which we call the 'innovative mode' (IM). The IM is mainly characterized by different layers of coffee powder with variable particle sizes. We compare the IM to a control, the conventional mode (CM). The detailed procedure to obtain the ground powder is described in the first trial reported in the followed section.

Three experiments were run to evaluate the extraction reliability of the IM. First, we tested different batches of coffee beans of the same commercial brand. Then we changed the type of coffee (different brands), and evaluated the effectiveness of IM and CM methods in terms of the need to manipulate the grinding setting. In the subsequent step, we blended different proportions of two, very different coffees to evaluate changes in the flow rate. 


\section{Trial 1: evaluation of different batches of the same commercial brand}

Five batches (A, B, C, D, E) of a coffee brand were selected (Caffè Motta Classico Lounge Bar, Via Roberto Wenner, 26 84,131 Salerno (SA) Italy). For each batch, the flow rate produced with standard, fixed granulometry powder $(\mathrm{CM})$ and with variable granulometry powder (IM) were measured. Coffee beans were ground using a KE640 ES/ VARIO flat grinder (Ditting, Hemro International AG Länggenstrasse 34 CH-8184 Bachenbülach), and extracted with a GS3 espresso machine (gs3, La Marzocco, Italy). Extraction parameters were water temperature $92{ }^{\circ} \mathrm{C}$ and water pressure 9 bar. Granulometry for the $\mathrm{CM}$ was configured to obtain a flow rate of $30 \mathrm{~g}$ in $30 \mathrm{~s}$, using $15 \mathrm{~g}$ of coffee powder pressed with a dynamometric tamper, from the first batch.

In Fig. 1, are shown examples of the particle size distribution (the bimodal profile) expressed on a logarithmic scale,for both coffee puck IM and CM, and relative characteristics measures expressed are as surface area, D [3, 4] and $\mathrm{D}[2,3]$ referred to as the volume mean diameters and different percentile diameters. For CM, a single particle distribution was reported, while for IM method, the particle size profile relative at each layer of powder was reported, ordered by the finest to the largest.

All these measurements have been performed with a particle sizing instrument based on laser diffraction (Malvern Mastersizer 3000, Grovewood Road, Malvern, Worcestershire, WR14 1XZ, United Kingdom).

The high peak (on the right, relating to larger particles) is called the 'first modal', while the lower peak (on the left,

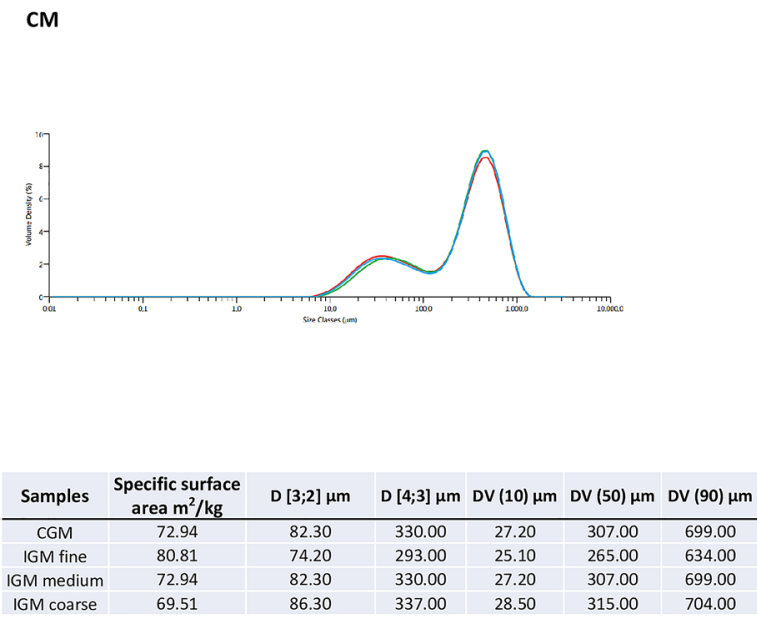

Fig. 1 Examples of the particle size distribution (the bimodal profile) expressed on a logarithmic scale,for both coffee puck IM and CM, and relative characteristics measures expressed are as surface area, D relating to smaller particles) is called the 'second modal'. From both the graphical representation and the table, it was possible to verify the grind size variation in the layers of IM powder. As for the CM method, the IM was setup to obtain $1 \mathrm{~g} \mathrm{~s}^{-1}$ average flow rate.

The total amount of powder was $15 \mathrm{~g}$ but different from the conventional method, three different layers of powder were obtained by varying manually the distance between the grinding plates.

The middle layer (composed by $5 \mathrm{~g}$ of powder) was obtained by the same setting used to produce the powder for CM. Then the grinding level was shifted to one notch above and below this standard position, to create three different ground powder.

The layers were assembly each composed of $5 \mathrm{~g}$ of coffee powder. These layers were arranged in the filter basket as shown in Fig. 2. The bottom layer was characterized by coarse particles, the middle by the same particle size also using for $\mathrm{CM}$ while the top layer was characterized by fine particles.

The inverse stratification (coarse particles on the top and fine on the bottom) was also tested. However, extraction was clearly a problem, probably due to the migration of the large particles and data are not reported. The instantaneous flow rate $\left(\mathrm{g} \mathrm{s}^{-1}\right)$ was recorded throughout the extraction (Orma BCE120, Capacity $1200 \mathrm{~g}$, Sensitivity $0.01 \mathrm{~g}$, plate $\varnothing 130 \mathrm{~mm}$, connected to a laptop) for five batches of both IM and CM. Each batch was tested with 15 extractions randomized to between each method followed the Latin letter order, previously reported, for the coffee batches. Each extraction was made entirely with powder ground at the moment, making a total of 150 extractions.

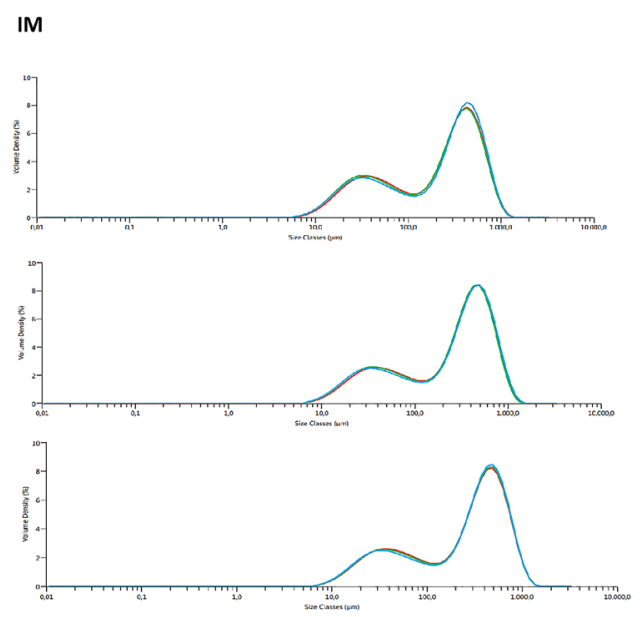

[34] and D[23] referred to as the volume mean diameters and different percentile diameters 
Fig. 2 The image on the left shows the conventional mode. The distribution of the particle size of the dose (D) inside the filter basket (FT) is fixed. The image on the right shows the innovative mode. Here, the distribution of the particle size varies; in this case, there are three layers

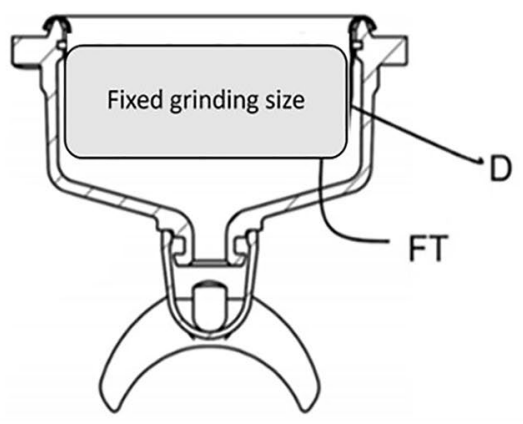

\section{Trial 2: evaluation of the IM applied to different brands of coffee}

Several types of coffee were chosen and tested with the same grinding machine (Ditting, Hemro International AG Länggenstrasse $34 \mathrm{CH}-8184$ Bachenbülach), and espresso was extracted with a GS3 espresso machine. Different brands of beans were purchased directly in a local store to account for variability in the coffee available on the market. Five brands were tested: Gimoka, blend $1000 \mathrm{~g}$ (Gruppo GIMOKA s.r.l. Andalo Valtellino, Sondrio-Italy); CORSINI ESPRESSO blend $1000 \mathrm{~g}$ (Corsino Corsini Via del Sembolino 62 Badia al Pino, Arezzo- Italy); Jolly Caffè Miscela Crema 1000 g (Jolly Caffè SpA, Firenze-Italy); Lavazza Crema e Gusto Espresso $1000 \mathrm{~g}$ (LUIGI LAVAZZA SPA, Italy); and Boasi Miscela Super Crema 1000 g (Caffè BOASI, Via Liverno, 7, 15,069 Serravalle Scrivia, Alessandria, Italy).

The grinder was set up for both IM and CM as described in the previous section. Once the correct setup was found for the first coffee brand, subsequent brands were ground without readjustment of the grinder settings, in order to observe flow rate variation due to the change of coffee brand in both IM and CM.

Variability was measured for 15 extractions in both modes (CM and IM), making a total of 150 extractions.

\section{Trial 3: evaluation of the reliability of the IM}

This trial evaluated the reliability of the IM and CM using a different methodological approach.

The aim of this step was to select two brands with very different flow rates, after grinding with the same setup. After a preliminary trial, coffees X (Illy 100\% Arabica 1000 g, illycaffè S.p.A., Via Flavia 110, 34,147 Trieste, Italy) and $\mathrm{Y}$ were selected (Coop Espresso Blend $1000 \mathrm{~g}$, Coop Italia S.C. Casalecchio di Reno (BO), Italy). Beans were ground using a professional flat grinder (EK43 Mahlkönig AG, Switzerland).

First, the CM was tested. Here, the flow rate for coffee $\mathrm{X}$ was $1 \mathrm{~g} \mathrm{~s}^{-1}$. Then coffee $\mathrm{Y}$ was ground with the same settings. This resulted in a flow rate that was almost double the rate of coffee $\mathrm{X}$, and outside the fixed tolerance of $\pm 15 \%$. This tolerance was chosen based on both our preliminary trials and the literature. Severini and coauthors [24] observed a variance in powder that ranged between 1 and $14 \%$, and showed that this was due to repeated grinding. Consequently, grinding with professional grinders, such as those commonly used in coffee shops, may have highly variable results. The two brands of coffee were also tested with the IM. Again, we first ground coffee $\mathrm{X}$, and then measured whether coffee $\mathrm{Y}$ was within the $15 \%$ set tolerance (above or below $1 \mathrm{~g} \mathrm{~s}^{-1}$ ).

In a second step, we measured the change in flow rate in blends of $\mathrm{X}$ and $\mathrm{Y}$ ground with the $\mathrm{CM}$ and IM techniques. The trial was considered to be finished when the measured flow rate fell outside the set tolerance $( \pm 15 \%)$. Fifteen replicates were performed for each blend of IM and CM.

\section{Statistical analysis}

In Trial 1, we compared the variance between the IM and the CM with an Analysis of Variance (ANOVA). The treatment (i.e. IM and CM) was considered fixed term in the ANOVA, while the different batches of coffee beans were treated as blocks (random effects $-p<0.05$ ). Furthermore, variance due to the different batches was compared by calculating the coefficient of variance (CV)\% for both methods and counting the number of batches that exceeded the tolerance threshold.

Variance due to the batch (Trials 2 and 3) was compared by calculating differences in flow rate (expressed as a percentage) for both methods and counting the number of batches that exceeded the tolerance threshold. Withinmethod variability was compared by assessing heteroskedasticity, using the $F$ test. 
Table 1 Comparison of the same coffee brand ground using the CM and IM methods (the latter is indicated with an *) expressed in terms of flow rate (mean \pm standard deviation), and the coefficient of variation $(\mathrm{CV})^{\mathrm{A}}$

\begin{tabular}{lllll}
\hline Batch & $\begin{array}{l}\text { Preparation } \\
\text { mode }\end{array}$ & Flow rate $\left(\mathrm{g} \mathrm{s}^{-1}\right)$ & $\mathrm{CV}(\%)$ & Variance \\
\hline $\mathrm{A} 1$ & $\mathrm{CM}$ & $1.09 \pm 0.08$ & 8 & 0.007 \\
$\mathrm{~A} 1^{*}$ & $\mathrm{IM}$ & $1.05 \pm 0.04$ & 4 & 0.001 \\
$\mathrm{~A} 2$ & $\mathrm{CM}$ & $1.02 \pm 0.08$ & 8 & 0.006 \\
$\mathrm{~A} 2^{*}$ & $\mathrm{IM}$ & $0.88 \pm 0.08$ & 9 & 0.007 \\
$\mathrm{~A} 3$ & $\mathrm{CM}$ & $1.15 \pm 0.07$ & 6 & 0.004 \\
$\mathrm{~A} 3 *$ & $\mathrm{IM}$ & $0.88 \pm 0.02$ & 2 & 0.0005 \\
$\mathrm{~A} 4$ & $\mathrm{CM}$ & $1.17 \pm 0.26$ & 22 & 0.067 \\
$\mathrm{~A} 4 *$ & $\mathrm{IM}$ & $0.93 \pm 0.12$ & 13 & 0.014 \\
$\mathrm{~A} 5$ & $\mathrm{CM}$ & $1.12 \pm 0.11$ & 10 & 0.012 \\
$\mathrm{~A} 5 *$ & $\mathrm{IM}$ & $0.79 \pm 0.05$ & 6 & 0.002 \\
\hline
\end{tabular}

A the underlined CV (\%) (22\%) indicates that the grinder must be recalibrated to achieve the correct espresso extraction

\section{Results and discussion}

\section{Trial 1: different batches of the same commercial coffee brand}

This first experiment aimed to evaluate the variability between IM and CM techniques. Table 1 shows the results.

In general, the results of the ANOVA showed that $\mathrm{CV} \%$ of IM was significantly lower $(p=0.01)$ than $\mathrm{CV} \%$ of $\mathrm{CM}$.

Specifically, in four of the five tested cases there was significantly lower flow rate variability for the same batch in extractions performed with the IM $(p<0.05)$. Moreover, in these batches the coefficient of variation $(\mathrm{CV} \%)$ was lower for the IM than the CM.

This experiment confirmed the wide variation in coffee beans (even for different batches of the same product) and underlined the importance of the relationship between the grinding setting and a constant flow rate. This situation reflects what happens in practice, as a barista typically uses the same coffee brand every day. Results from our five batches indicated that the grinder settings should be changed once with the CM to guarantee the stability of the beverage, while no changes were required with the IM.

The instantaneous flow rate was recorded to assess its stability within extractions. The results are reported in Fig. 3. Several studies have demonstrated that the aromatic profile of espresso and its chemical attributes are deeply affected by the instantaneous flow rate during extraction, which itself is a function of the grade of the ground coffee $[3,20,26]$. Results from CM studies highlight that the majority of organic acids, solids, and caffeine are extracted during the first $8 \mathrm{~s}$ of percolation [7]. Typically, the flow rate is lowest at the beginning of the extraction; it increases

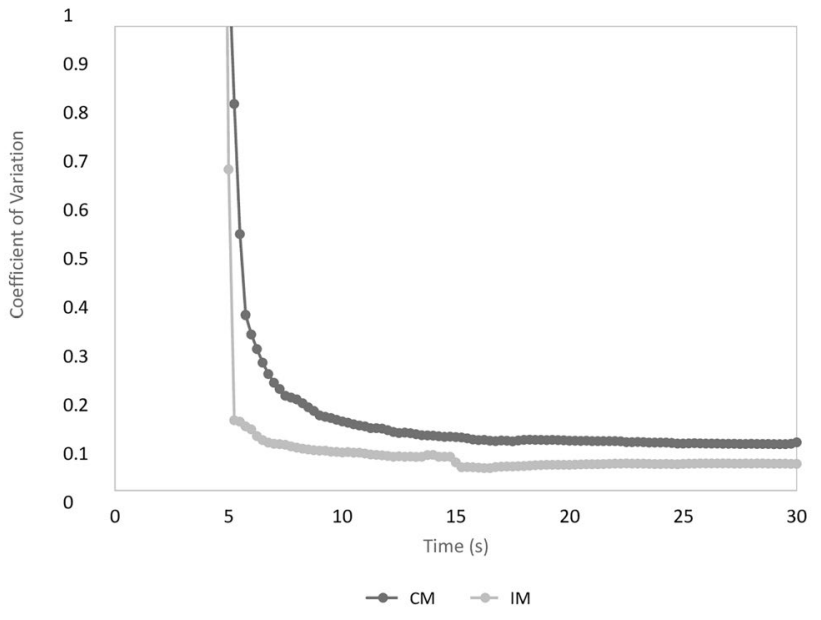

Fig. 3 Coefficient of variation for the conventional (CM) and innovative mode $(\mathrm{IM})(n=15$ extractions $) 338 \times 190 \mathrm{~mm}(200 \times 200 \mathrm{DPI})$

over the following $20 \mathrm{~s}$, while concentrations of chemical constituents fall.

Figure 3 reports the $\mathrm{CV}$ for both IM and CM during the $30 \mathrm{~s}$ extraction time. Initially (after roughly $5 \mathrm{~s}$ for both methods), variation was lower for the IM than the CM. This trend lasted for the whole extraction. Moreover, differences in the instantaneous flow rate were smaller for the IM, indicating greater stability over time. Finally, at the end of the extraction, the $\mathrm{CV}$ was higher for the $\mathrm{CM}(11 \%)$ compared to the IM (6\%). Higher CV is consistent with a poorer extraction, due to a less homogeneous flow pattern, dead zones in the flow, the agglomeration of fine particles or, in the worst case, regions of dry coffee in the bed. The development of flow channels (channeling), in shallow or poorly tamped beds is a particular problem that baristas have to avoid when brewing espresso coffee [27].

The high CV recorded at the beginning of the extraction (regardless of the method) is due to the coffee powder wetting time. Our instantaneous flow rate of $\mathrm{CM}$ is consistent with the literature [7].

\section{Trial 2: evaluation of the IM applied to different brands of coffee}

In Trial 2, different coffee brands were used to test the reliability of IM and CM as a function of the raw material (the coffee beans).

The first row of Table 2 (A and $\mathrm{A}^{*}$ ) corresponds to the coffee used as a reference, while the asterisk indicates the different preparation modes. The third column reports measured flow rates, while the last column indicates the difference in flow rate compared to the reference. For two of the four brands ( $B$ and $D$ ) the flow rate was similar to the reference brand (A) and within the tolerance threshold. In these 
Table 2 Comparison of coffee brands ground using the CM and IM techniques (the latter is indicated by an *) expressed in terms of flow rate (mean \pm standard deviation) and difference $\%{ }^{\mathrm{A}}$

\begin{tabular}{llll}
\hline Samples & $\begin{array}{l}\text { Preparation } \\
\text { mode }\end{array}$ & Flow rate $\left(\mathrm{g} \mathrm{s}^{-1}\right)$ & Difference (\%) \\
\hline A & CM & $1.24 \pm 0.06$ & \\
A $^{*}$ & IM & $1.24 \pm 0.02$ & 0 \\
B & CM & $1.09 \pm 0.10$ & 12 \\
B $^{*}$ & IM & $1.13 \pm 0.07$ & 8 \\
C & CM & $0.93 \pm 0.06$ & 25 \\
C* $^{*}$ & IM & $1.25 \pm 0.07$ & -1 \\
D & CM & $1.20 \pm 0.08$ & 3 \\
$D^{*}$ & IM & $1.25 \pm 0.05$ & -1 \\
E & CM & $0.81 \pm 0.15$ & 35 \\
E* $^{*}$ & IM & $1.15 \pm 0.19$ & 7 \\
\hline
\end{tabular}

A The underlined difference (\%) indicates that the grinder must be recalibrated to achieve the correct espresso extraction

cases, no differences were found between the two preparation systems, which is beneficial for the barista. Here, the grinder settings need not be changed between coffees $\mathrm{A}$ and B/D.

However, this was not the case for brands $\mathrm{C}$ and E. Here, extraction flow rates exceeded the tolerance threshold for the CM. CM flow rates were 25\% (brand C) and 35\% (brand E) higher than the reference flow rate. On the other hand, IM flow rates remained within the tolerance threshold $(-1$ and $7 \%$, respectively). In practical terms, a barista who uses the $\mathrm{CM}$ will have to change the grinding settings for two of the four brands, while a barista who uses the IM will not have to change anything. This is a significant improvement, as baristas who have to change the grinding setting waste powder and time searching for the correct configuration.

\section{Evaluation of the reliability of the IM}

The results shown in Table 3 confirm the observations of Trials 1 and 2. Using the same grinder settings, the flow rates of coffees $\mathrm{X}$ and $\mathrm{Y}$ changed considerably. Specifically, the flow rate for coffee $\mathrm{Y}$ was roughly double that obtained with coffee $\mathrm{X}$, which confirmed that the grinding level chosen for one coffee was not appropriate for the other.

For the $80 \% \mathrm{X}+20 \% \mathrm{Y}$ blend, the CM flow rate was unsuitable for espresso extraction (a difference of $25 \%$ compared to the $15 \%$ tolerance threshold), while the IM flow rate did not change. The same unacceptable result was found for the $\mathrm{CM}$ using the $70 \% \mathrm{X}+30 \% \mathrm{Y}$ blend, while the IM flow rate decreased by $5 \%$.

We did not investigate the CM for higher proportions of $\mathrm{Y}$ as the range of values was already sufficiently different. Using the IM, the flow rate exceeded the tolerance threshold (by 46\%) with the $50 \% \mathrm{X}+50 \% \mathrm{Y}$ blend. The results obtained from this experiment highlight the potential reliability of the IM. Moreover, they show that up to $40 \%$ of the powder can be ground at the wrong size with no adverse effects on flow rate.

Overall, our trials show that the proposed approach could be a convenient way to manage coffee beans. This is especially important as the raw material has a high degree of variability: (i) within batches of the same brand; (ii) among different brands; and (iii) in blends of coffee beans. A grinder that is more robust to variation in the raw material could help the barista to consistently guarantee coffee quality without having to change the grinder setting.
Table 3 Comparison of coffee brands $\mathrm{X}$ and $\mathrm{Y}$ ground using the CM and IM techniques (the latter is indicated by an *), and mixed in different proportions, expressed in terms of flow rate (mean \pm standard deviation), coefficient of variation, ratio and difference $\%^{\mathrm{A}}$

\begin{tabular}{lllllll}
\hline Coffee & Blend composition & $\begin{array}{l}\text { Prepara- } \\
\text { tion mode }\end{array}$ & Flow rate $\left(\mathrm{g} \mathrm{s}^{-1}\right)$ & CV (\%) & Ratio & Difference (\%) \\
\hline $\mathrm{X}$ & $100 \%$ & $\mathrm{CM}$ & $0.97 \pm 0.05$ & 5.5 & 1 & \\
$\mathrm{Y}$ & $100 \%$ & $\mathrm{CM}$ & $2.05 \pm 0.07$ & 3.6 & 2.11 & 111 \\
$\mathrm{X}^{*}$ & $100 \%$ & $\mathrm{IM}$ & $1.06 \pm 0.06$ & 5.5 & 1.00 & \\
$\mathrm{Y}^{*}$ & $100 \%$ & $\mathrm{IM}$ & $1.96 \pm 0.06$ & 3.0 & 1.85 & 85 \\
$\mathrm{X}+\mathrm{Y}$ & $\mathrm{X}(80 \%)+\mathrm{Y}(20 \%)$ & $\mathrm{CM}$ & $1.22 \pm 0.06$ & 4.7 & 1.25 & 25 \\
$\mathrm{X}+\mathrm{Y}$ & $\mathrm{X}(70 \%)+\mathrm{Y}(30 \%)$ & $\mathrm{CM}$ & $1.47 \pm 0.16$ & 10.7 & 1.52 & 52 \\
$\mathrm{X}^{*}+\mathrm{Y}^{*}$ & $\mathrm{X}^{*}(80 \%)+\mathrm{Y}^{*}(20 \%)$ & $\mathrm{IM}$ & $1.06 \pm 0.05$ & 4.7 & 1.00 & 0 \\
$\mathrm{X}^{*}+\mathrm{Y}^{*}$ & $\mathrm{X}^{*}(70 \%)+\mathrm{Y}^{*}(30 \%)$ & $\mathrm{IM}$ & $1.01 \pm 0.06$ & 6.0 & 0.95 & -5 \\
$\mathrm{X}^{*}+\mathrm{Y}^{*}$ & $\mathrm{X}^{*}(60 \%)+\mathrm{Y}^{*}(40 \%)$ & $\mathrm{IM}$ & $1.09 \pm 0.03$ & 2.9 & 1.03 & 3 \\
$\mathrm{X}^{*}+\mathrm{Y}^{*}$ & $\mathrm{X}^{*}(50 \%)+\mathrm{Y}^{*}(50 \%)$ & $\mathrm{IM}$ & $1.55 \pm 0.11$ & 7.1 & 1.46 & 46 \\
\hline
\end{tabular}

A the underlined difference (\%) indicates that the grinder must be recalibrated to achieve the correct espresso extraction 


\section{Conclusions}

The aim of our work was to evaluate an innovative method to prepare coffee powder puck that is able to reduce the sensitivity of a grinding machine to variation in coffee beans. Our goal, which was directly connected to the flow rate, was achieved using three, stratified layers of ground coffee with different particle size. More particularly, flow rate robustness could be improved by placing larger particles at the bottom, and finer particles at the top of the filter basket.

Our experiments highlighted that the new coffee puck system was more stable, in terms of flow rate, than a conventional system, either using homogeneous raw materials (the same brand of beans), very heterogenous materials (different brands of beans), or blends of different materials. This patented solution could be adopted by baristas who require a consistent product. It appears to be a promising solution to the troublesome problem of offering low-quality products to consumers and/or reducing waste (in terms of time and coffee) due to the need to correct the grinder setup.

Acknowledgements The authors gratefully acknowledge La Marzocco s.r.l., for providing coffee machines and for their support during the experiments.

Funding Open access funding provided by Università degli Studi di Firenze within the CRUI-CARE Agreement. No funding to declare.

\section{Declarations}

Conflict of interest The academic authors are the inventor of the patented solution reported in the scientific article and they have not financial interests in the patent exploitation. The industrial authors are the inventor of the patented solution and have working relationships with the patent owner.

Compliance with ethics requirements This study does not contain any studies with human participants or animals performed by any of the authors.

Open Access This article is licensed under a Creative Commons Attribution 4.0 International License, which permits use, sharing, adaptation, distribution and reproduction in any medium or format, as long as you give appropriate credit to the original author(s) and the source, provide a link to the Creative Commons licence, and indicate if changes were made. The images or other third party material in this article are included in the article's Creative Commons licence, unless indicated otherwise in a credit line to the material. If material is not included in the article's Creative Commons licence and your intended use is not permitted by statutory regulation or exceeds the permitted use, you will need to obtain permission directly from the copyright holder. To view a copy of this licence, visit http://creativecommons.org/licenses/by/4.0/.

\section{References}

1. ICO. International Coffee Organization., (2018) https://www.ico. org/monthly_coffee_trade_stats.asp. Accessed 2 Sep 2020
2. Andueza S, Paz De Peña M, Cid C (2003) Chemical and sensorial characteristics of espresso coffee as affected by grinding and torrefacto roast. J Agric Food Chem 51:7034-7039. https://doi. org/10.1021/jf034628f

3. Angeloni G, Guerrini L, Masella P, Bellumori M, Daluiso S, Parenti A, Innocenti M (2019) What kind of coffee do you drink? An investigation on effects of eight different extraction methods. Food Res Int. https://doi.org/10.1016/j.foodres.2018.10.022

4. Cordoba N, Fernandez-Alduenda M, Moreno FL, Ruiz Y (2020) Coffee extraction: a review of parameters and their influence on the physicochemical characteristics and flavour of coffee brews. Trends Food Sci Technol 96:45-60

5. Angeloni G, Guerrini L, Masella P, Innocenti M, Bellumori M, Parenti A (2019) Characterization and comparison of cold brew and cold drip coffee extraction methods. J Sci Food Agric. https:// doi.org/10.1002/jsfa.9200

6. Angeloni G, Masella P, Guerrini L, Innocenti M, Bellumori M, Parenti A (2019) Application of a screening design to recover phytochemicals from spent coffee grounds food Bioprod. Process. https://doi.org/10.1016/j.fbp.2019.08.017

7. Severini C, Ricci I, Marone M, Derossi A, De Pilli T (2015) Changes in the aromatic profile of espresso coffee as a function of the grinding grade and extraction time: a study by the electronic nose system. J Agric Food Chem 63:2321-2327. https:// doi.org/10.1021/jf505691u

8. Masella P, Guerrini L, Spinelli S, Calamai L, Spugnoli P, Illy F, Parenti A (2015) A new espresso brewing method. J Food Eng 146:204-208. https://doi.org/10.1016/j.jfoodeng.2014.09.001

9. Gloess AN, Schönbächler B, Klopprogge B, D’Ambrosio L, Chatelain K, Bongartz A, Strittmatter A, Rast M, Yeretzian C (2013) Comparison of nine common coffee extraction methods: instrumental and sensory analysis. Eur Food Res Technol 236:607-627. https://doi.org/10.1007/s00217-013-1917-x

10. Petracco M (2008) Technology IV: beverage preparation: brewing trends for the new millennium. Coffee Recent Dev. https:// doi.org/10.1002/9780470690499.ch7

11. Albanese PMSSD, DiMatteo M (2009) Espresso coffee (EC) by POD: study of thermal profile during extraction process and influence of water temperature on chemical-physical and sensorial properties. Food Res Int 42:727-732

12. Illy E, Navarini L (2011) Neglected Food Bubbles: the Espresso Coffee Foam. Food Biophys 6:335-348. https://doi.org/10.1007/ s11483-011-9220-5

13. Illy R, Viani A (1995) Espresso coffee: The chemistry of quality. Academic Press, London

14. Moroney J, Lee KM, Suijver WT, Marra F (2015) Modelling of coffee extraction during brewing using multiscale methods: an experimentally validated model. Chem Eng Sci 137:216-234

15. Folmer AP, Blank B, Hofmann I (2017) Crema-formation, stabilization, and sensation. Cr Sci Coffee 399-417

16. Angeloni G, Masella P, Guerrini L, Spadi A, Bellumori M, Innocenti M, Parenti A (2020) Physical and chemical effects of different working gases in coffee brewing : a case study of Caffè Firenze. Foods 9(12):1825

17. Doğan M, Aslan D, Gürmeriç V, Özgür A, Göksel Saraç M (2019) Powder caking and cohesion behaviours of coffee powders as affected by roasting and particle sizes: Principal component analyses PCA for flow and bioactive properties. Powder Technol 344:222-232. https://doi.org/10.1016/j.powtec.2018. 12.030

18. Salamanca CA, Fiol N, González C, Saez M, Villaescusa I (2017) Extraction of espresso coffee by using gradient of temperature Effect on physicochemical and sensorial characteristics of espresso. Food Chem 214:622-630. https://doi.org/10.1016/j. foodchem.2016.07.120 
19. Derossi C, Ricci A, Caporizzi I, Fiore R, Severini A (2018) How grinding level and brewing method Espresso American Turkish could affect the antioxidant activity and bioactive compounds in a coffee cup. J Sci Food Agric 98:3198-3207

20. De Vivo A, Tricarico MC, Sarghini F (2019) Espresso coffee design based on non-monotonic granulometric distribution of aromatic profile. Food Res Int 123:650-661. https://doi.org/10. 1016/j.foodres.2019.05.027

21. Corrochano BR, Melrose JR, Bentley AC, Fryer PJ, Bakalis S (2015) A new methodology to estimate the steady-state permeability of roast and ground coffee in packed beds. J Food Eng 150:106-116. https://doi.org/10.1016/j.jfoodeng.2014.11.006

22. Uman E, Colonna-Dashwood M, Colonna-Dashwood L, Perger M, Klatt C, Leighton S, Miller B, Butler KT, Melot BC, Speirs RW, Hendon $\mathrm{CH}$ (2016) The effect of bean origin and temperature on grinding roasted coffee. Sci Rep 6:1-8. https://doi.org/10.1038/ srep24483

23. Kuhn M, Lang S, Bezold F, Minceva M, Briesen H (2017) Timeresolved extraction of caffeine and trigonelline from finely-ground espresso coffee with varying particle sizes and tamping pressures. J Food Eng 206:37-47. https://doi.org/10.1016/j.jfoodeng.2017. 03.002

24. Severini C, Derossi A, Fiore AG, De Pilli T, Alessandrino O, Del Mastro A (2016) How the variance of some extraction variables may affect the quality of espresso coffees served in coffee shops. J Sci Food Agric 96:3023-3031. https://doi.org/10.1002/jsfa.7472

25. Robert MS, Selwood M (1984) The kinetics and mechanism of caffeine infusion from coffee: The effect of particle size. Sci Food Agric 35:915-924

26. Khamitova G, Angeloni S, Borsetta G, Xiao J, Maggi F, Sagratini G, Vittori S, Caprioli G (2020) Optimization of espresso coffee extraction through variation of particle sizes, perforated disk height and filter basket aimed at lowering the amount of ground coffee used. Food Chem 314:126220. https://doi.org/10.1016/j. foodchem.2020.126220

27. Moroney KM, O'Connell K, Meikle-Janney P, O'Brien SBG, Walker GM, Lee WT (2019) Analysing extraction uniformity from porous coffee beds using mathematical modelling and computational fluid dynamics approaches. PLoS ONE 14:1-24. https://doi.org/10.1371/journal.pone.0219906

Publisher's Note Springer Nature remains neutral with regard to jurisdictional claims in published maps and institutional affiliations. 